\title{
Instrumentation and Controls Instruction for Agricultural and Biological En- gineering Students
}

\section{Prof. George E. Meyer, University of Nebraska - Lincoln}

There is a co-author.

GEORGE MEYER, Professor, has taught graduate and undergraduate classes that involve plant and animal growth and environmental factors, modeling, and instrumentation and controls for both agricultural and biological systems engineering students for 38 years. He specializes in electronic instrumentation, sensors, controls, thermal and spectral image analysis for plant growth response, water use and stress; crop, weeds, machine vision identification and enumeration of plant species for field and greenhouse production. Winter-time greenhouse strawberry and herb production are recent funded research activities.

YUFENG GE, Assistant Professor of Biological Systems Engineering, University of Nebraska. Dr. Ge obtained his $\mathrm{PhD}$ in Biological and Agricultural Engineering at Texas A\&M University. He started as a teaching assistant for the sensor and instrumentation class there in 2005, and gradually increased his teaching responsibility for the class to become a co-instructor (since 2010) and instructor (2013). He was the faculty advisor for the student robotics teams who competed for the ASABE robotics competitions in 2012 and 2013.

Dr. Yufeng Ge, University of Nebraska - Lincoln 


\title{
Instrumentation and Controls Instruction for Agricultural and Biological Engineering Students
}

\begin{abstract}
Modern agricultural and biological systems use electronic sensors, instrumentation, and computers for acquisition of scientific data and process control. Instrumentation is used for commercial product development, testing, and for basic research. An instrumentation and controls course for agricultural and biological engineering pre-professionals addresses sensors, measurement principles, software, and limitations of such systems with hands-on laboratory activities will be discussed. This is a core course for two ABET accredited biological and agricultural engineering degree programs. Students participate and interact in small teams for a course with enrollments of 60 students or more. The course assumes the student to be a junior, senior, or first year graduate student who has completed an introductory electronics course and most core and elective courses. Weekly laboratory activities include bread boarding of basic instrumentation circuits followed by specialty exercises on sensor response times and controls. Two signature laboratories include open channel and pipe flow water flow measurements and an internal combustion engine test exercise. Student teams also develop semester projects which are presented as posters and papers at an annual department open house. Student projects investigate electrocardiograms, temperature and humidity control, human exercise measurements, force, power, and energy consumption, detection and controls using optical sensors, and water quality, using commercially available devices. A summary of student team projects and outcomes for the past offering will be discussed. Student activities are assisted with oscilloscopes, precision power supplies, moderate LabVIEW programming, and multifunction devices. Instructional aides are presented in detailed handouts, materials written by the instructors, and other readily available sources.
\end{abstract}

Keywords: Courseware, sensors, instrumentation fundamentals, electronics, laboratory instruction.

\section{Course Concepts}

Modern agricultural, biological, and biomedical instrumentation uses electronic sensors, analog and digital circuits, computers and microcontrollers for scientific measurements and process control. Instrumentation is used widely for commercial product development, testing, and basic research. The course described in this paper introduces basic measurement theory, applications of instrumentation and controls along with features of basic biological, environmental, and mechanical sensors. Sensors and transducers introduced include contact, non-contact, mechanical, thermal, optical, ultrasonic, and other devices.

The topic areas of the course given 2015 are presented in Table 1. During the first five weeks, there is an intensive introduction to the understanding of fundamental instrumentation electronics. Many instrumentation textbooks cover analog and digital principles for instrumentation in different formats ${ }^{1,2}$. Each topic offered in the curriculum addresses practical instrumentation and control examples through hands-on laboratory exercises, demonstrations, and preparation of a final team project. Before any team project, formal and required laboratory exercises are 
undertaken. They include experiments with hands-on bread boarding fundamental electronic circuits and activities with temperature sensing, fluid flow, stress-strain, and optical sensors. Computer interfacing with instrumentation is presented to the students with pre-written and available LabVIEW virtual instruments or programs. There is a modest emphasis on programming.

A number of instrumentation books are available, either as monographs ${ }^{3,4,5}$, textbooks ${ }^{6,7}$, and small, but significant paperbacks ${ }^{8,9}$. Many currently available text books depend on the student's discipline or background. There has been a recent proliferation of instrumentation monographs, many of which are included in the reference list. Monographs are best used as library reserve resource materials. Some books feature a programming language for instrumentation and controls $^{10,11,12,13}$. Refereed instrumentation papers are certainly of interest to senior agricultural and biological engineers, but may not provide the necessary practice problems needed. If one searches the internet, students will find numerous commercial sensors and instrumentation sites, and possibly be overwhelmed by the plethora of technical information. Sufficient background and experience to evaluate and select such systems is what is specifically needed.

Over the years, it had become apparent that many instrumentation textbooks have been written for special audiences in various fields of engineering. A new text book is being completed by the authors, which provides the student the opportunity to understand and gain practical experience with modern measurement equipment, data acquisition, and digital control systems for this discipline. This book is presented to the students as a set of pdf chapters ${ }^{14}$. The course assumes that the student is a junior, senior pre-engineer, or a first-year graduate student. It is a required course for two ABET accredited biological systems and agricultural engineering programs at the University of Nebraska. The course bulletin information is given in Appendix A

\section{Course Objectives}

The objectives and expected outcomes of this course are to ${ }^{1}$ :

1. Recall technical language, terms, and definitions for electronic sensors, instrumentation, and control. (Remembering)

2. Recognize and identify the physical mechanisms of basic sensors and how they interact with the measurand for biological, biomedical, and agricultural applications. (Understanding)

3. Demonstrate the ability to select instrumentation and controls components in order to design, assemble, and operate a measurement system for specific applications. (Applying)

4. Differentiate applications for electronic sensors and modern data-logging equipment (Analyzing)

5. Design, develop and communicate a specific measurement system relative to area of technical interest (Creating)

6. Present and defend a project with an electronic instrumentation system at a public forum. (Evaluating).

\footnotetext{
${ }^{1}$ Corresponding to New Bloom's Taxonomy (web.odu.edu/educ/llschult/blooms_taxonomy.htm)
} 


\section{Course Design}

This course provides the student the opportunity to assemble and operate modern electronic measurement equipment, including an oscilloscope, data acquisition, microcontrollers, and digital control systems (Table 1). The course assumes the student has had a basic physics course and has taken most of the core agricultural and biological systems engineering courses. This course addresses practical instrumentation and control systems through hands-on laboratory exercises, and in-class demonstrations. Course objectives 1-4 are incorporated in all of these latter activities. Finally, a semester student team project is assigned from an extensive list of possible project ideas, leading to course objective 5 . Some of these ideas are proposed by industry contacts, while others are proposed by the faculty. Student teams present their projects as posters during the annual Departmental Open House each December at the end of the fall semester (course objective 6). Project reports are evaluated using the rubric shown in Appendix B. Over the years, some of the very best student team projects have been chosen to become regular laboratory activities. Processing of homework, laboratory reports, quizzes, and the final team project is done by electronic collection, grading, distribution of grades and rubrics for the students ${ }^{15}$. Using a modern, efficient grading and evaluation system was very useful for a fall 2015 enrollment of 60 students.

\section{Table 1. Instrumentation and Controls - Schedule of Topics.}

Review of electronics and Circuits:

- DC and AC

- Ohm's law, KCL, KVL, circuit analysis

- Resistance, capacitance, impedance

- Voltage divider and Wheatstone bridge

- Thevenin equivalent circuit

- Loading effects

Semiconductors:

- Semiconductor materials, doping

- P-N junction

- Diodes and special purpose diodes

- Transistors, BJT and MOSFET

- TTL and CMOS

- Integrated circuits

Digital signal processing:

- Sampling and Quantization

- Binary number system

- Combinatory and sequential logic gates

- $\mathrm{A} / \mathrm{D}$ and $\mathrm{D} / \mathrm{A}$ conversion

- Data acquisition system

- A brief introduction to microcontroller systems

Analog signal processing: 
- Op-amps and In-amps, various feedback configuration of op-amps

- Time domain and frequency domain

- High-pass and low-pass filter, bode diagram, RC filter circuit design

Sensors:

- Sensor basics - precision, accuracy, and resolution; $1^{\text {st }}$ order response, calibration

- Temperature sensor - RTD, thermistor, thermocouple, infrared thermal sensor

- Force sensor - strain gages and load cells

- Optical sensor - photodiode - based optic sensing and fiber optics

- Electrochemical sensing

Actuators:

- Brushed DC motor principle

- Pulse width modulation and H-bridge bidirectional drive

- Motor speed control

- Step motor and motor drive

Controls:

- Process control diagram

- Open loop and closed loop control

- ON-OFF and PID control

- Computer based supervisory control

\section{Signature Laboratory Exercises}

The first twelve weeks of the semester are devoted to formal laboratory exercises, assembly and testing of fundamental electronic instrumentation circuits, and the preparation of good, but concise lab reports (Table 2). Laboratory reports are usually limited to a 2-page narrative, typical of the size expected by industry. The dynamics and characteristics of electronic sensors are very important topics for measurements. Students learn operate a modern digital oscilloscope (Model 1002b, Tektronix, Inc., Beaverton, OR). Students analyze unknown signals provided by a signal generator, which include sinusoidal, square, and impulse signals. The second lab is devoted to wiring and soldering skills (a lost art) in the construction of a microphone circuit. The response time of sensors and the aperture time of sample frequency of analog-digital conversion is also important in matching instrumentation to desired measurement objectives. The students study the response time of various temperature sensors which include thermocouple, thermistors, integrated temperature sensors, and infrared sensors.

Table 2. Scheduled Laboratories

$\begin{array}{ll}\text { Week } 1 & \text { Electronic components and circuits } \\ \text { Week } 2 & \text { Functional generator and oscilloscope, 555 Timer } \\ \text { Week } 3 & \text { Assembling and testing a microphone } \\ \text { Week } 4 & \text { LabVIEW programming; Turn on and off LED } \\ \text { Week } 5 & \text { Signal generation, filtering, and analysis }\end{array}$




$\begin{array}{ll}\text { Week } 6 & \text { Pipe and open channel water flow sensors and measurements } \\ \text { Week } 7 & \text { Temperature sensors and their response time } \\ \text { Week } 8 & \text { Optical sensing }- \text { optical density measurement } \\ \text { Week } 9 & \text { Fall break } \\ \text { Week } 10 & \text { Performance of diesel engine } \\ \text { Week } 11 & \text { Calibration of Load Cells / Vernier Physiology Sensors. } \\ \text { Week } 12 & \text { Speed control of electric motor } \\ \text { Weeks } 13 \sim 15 & \text { Class project }\end{array}$

\section{$\underline{\text { Bread boarding }^{2}}$}

The breadboard, shown in Figure 1 is a platform used to build, test and modify electrical circuits very easily for instrumentation. Breadboards come in handy when one performs experiments or conducts research and design work. Some disadvantages of breadboards are (1) they do not function well in higher frequency experiments, and (2) sometimes they are not very reliable. To build a permanent circuit, the student can use a Vero board or a printed circuit board (PCB). The most important thing to learn about the breadboard is how holes are connected. As a rule of thumb, any five holes in the same row are connected (or short circuited). The two vertical columns at each side are connected, and they are usually used as positive and negative power rails. If one flips over the breadboard and looks at the metal connections, the student will have a better idea of how electrical components should be placed on the board, in particular how an IC (integrated circuit, with multiple pins) component should be placed.

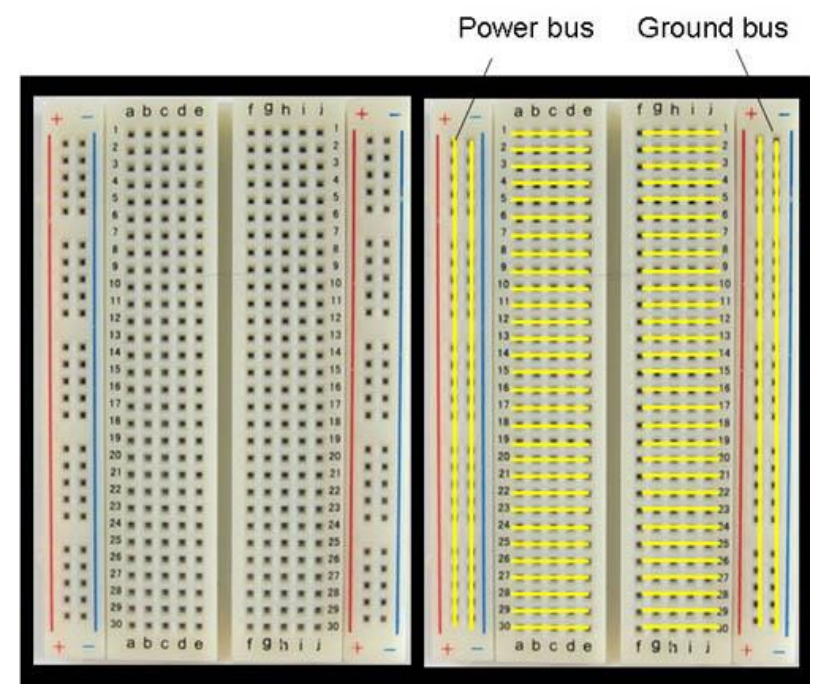

Figure 1. Breadboard and illustration of connections.

\footnotetext{
${ }^{2}$ Mention of specific trade names is for reference only and not to imply exclusion of others that may be suitable.
} 


\section{Using the NI myDAQ as an Oscilloscope and Controller with Bread Boarded Circuits}

Often, it is necessary to integrate a breadboard with a simple multi-function digital device. The National Instruments (Austin, TX) myDAQ is very compact and portable so students can extend hands-on learning outside of the lab environment using industry-standard tools and methods (Figure 2). The NI myDAQ includes two analog inputs and two analog outputs at $200 \mathrm{kS} / \mathrm{s}$ and 16 bits, allowing for applications such as sampling an audio signal; eight digital inputs and output lines, providing power for simple circuits with $+5,+15$, and -15 volt power supplies; and a $60 \mathrm{~V}$ DMM to measure voltage, current, and resistance.

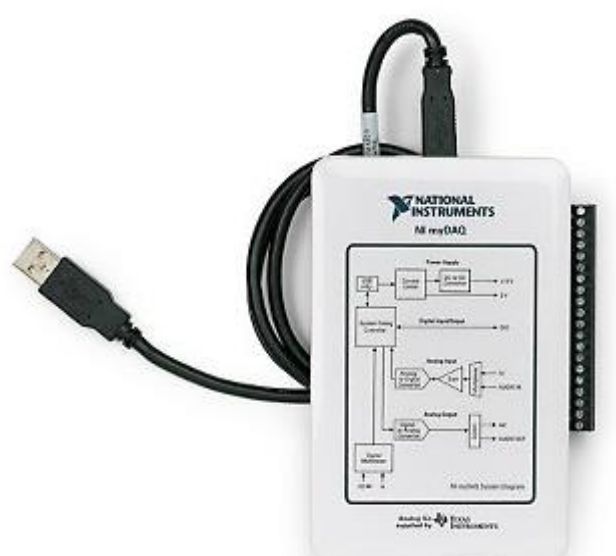

Figure 2. National Instruments MyDAQ Multifunction device (Courtesy: NI.com).

\section{$\underline{\text { Measuring Time Constants for Various Temperature Sensors }}$}

System response is often a very important process in instrumentation. The time required for a physical quantity to rise from zero to $1-1 / \mathrm{e}$ or $63.2 \%$ of its final steady value, as it varies with time $\mathrm{t}$ as $1-\mathrm{e}^{-\mathrm{k} \cdot \mathrm{t}}$, is denoted as a time constant $\tau$. (In contrast, the time required for a physical quantity to fall to $1 / \mathrm{e}$ or $36.8 \%$ of its initial value when it varies with time). Generally, the time required for an instrument or sensor to reach a given percentage of the final reading resulting from an input signal may also be known as a lag coefficient. The same kind of reasoning also applies to finding time constants for step responses. Cold air baths with water and ice in thermos bottles are provided, so some precautions need to be taken to avoid shorting out thermocouples and thermistors. A step change in temperature is applied for each sensor (Figure 3). Temperature-time measurements for each heating and cooling sequence are repeated three times. A decay function is found for cooling. A rise function is found for heating. 


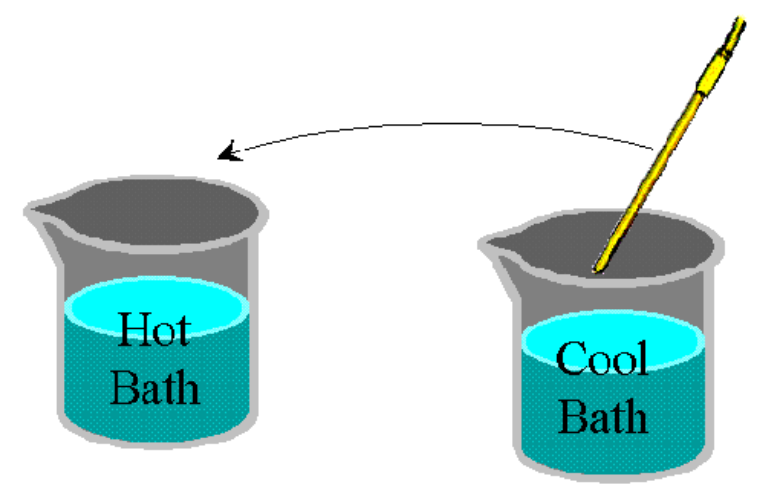

Figure 3. A Step Change in Temperature using a thermometer.

A pre-written supplied LabVIEW "state Machine" and an NI Compact DAQ (cDAQ)® using either an NI 9211 temperature module or the NI 9219 universal module, as appropriate were used with a thermistor and various thermocouples. The response times of each sensor using were calculated by the students, accordingly.

Students are introduced to National Instruments commercial data acquisition hardware such as the compact DAQ (cDAQ), shown in Figure 3. Various sensor modules are available from NI and can be easily hot-swapped with the CDAQ chassis, so that various modules can be shared and used at different student work stations. The NI 9211 4-Channel, 14 Samples/s, 24-Bit, $\pm 80 \mathrm{mV}$ Thermocouple Input Module is shown in Figure 4a. The 24-Bit Universal Analog Input module shown in Figure 4b, c may be used for thermocouples, thermistors, RTD's, and a variety of bridge configuration. Any module can be installed in an available cDAQ Slot. Each module is automatically identified with a LabVIEW DAQmx software setup. 110 AC power must be applied to the four-slot cDAQ. The single slot cDAQ version can draw its power through the USB cable.

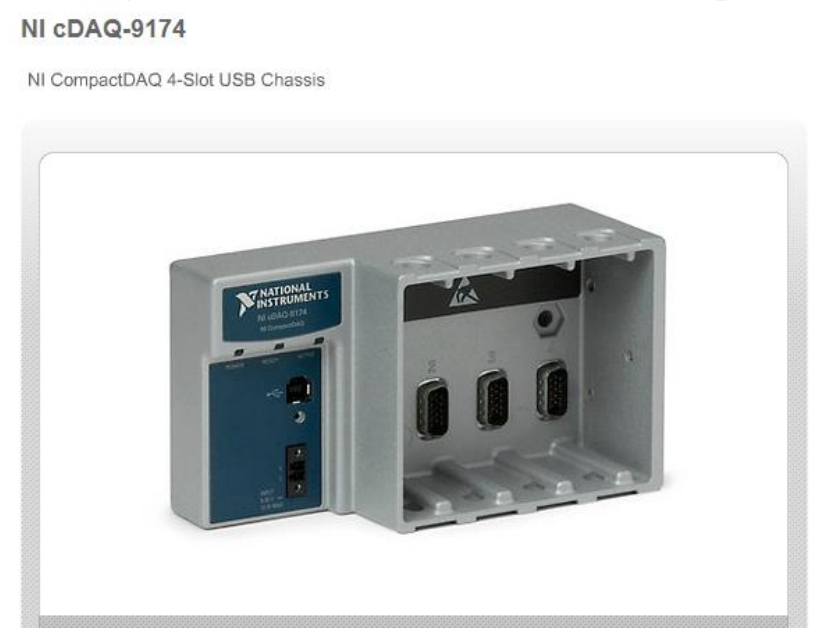

Figure 4a. USB, NI cDAQ, 4-Slot USB Chassis.
Counter/Timer Input, Analog Output, Digital Input, Analog Input, and Digital Output (Courtesy: NI.com). 


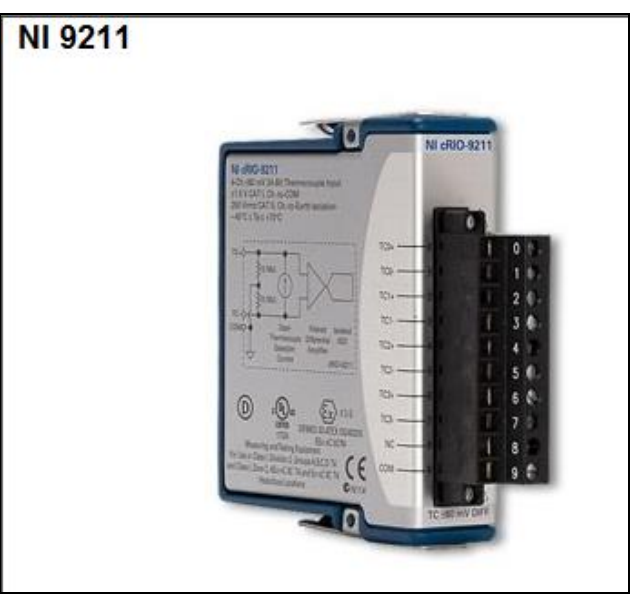

Figure 4b. 4-Channel, 14 S/s, 24-Bit, \pm 80 $\mathrm{mV}$ Thermocouple Input Module.

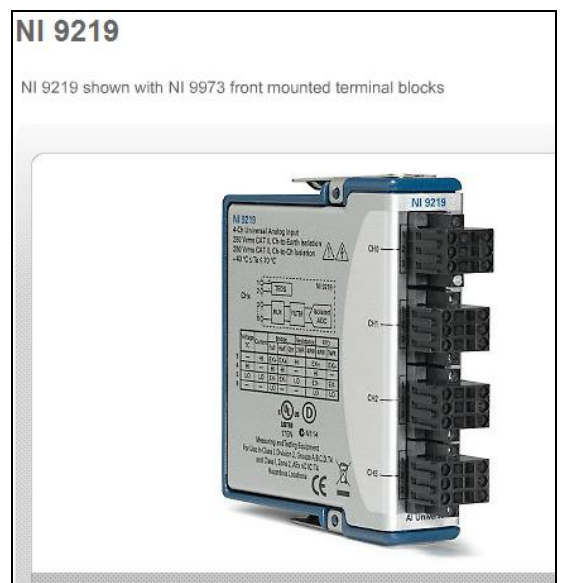

Figure 4c. 24-Bit Universal Analog Input. (Courtesy: NI.com).

For the Processing state of the program (to obtain response times), a XY Graph Chart Cursor system with Property Nodes are added by the students to create active cursors for determining time constants right off the Response Waveform Graph using the mouse (Figure 5). The LabVIEW XY graph property nodes, allows the student to create and move cursors (called the active cursor ActCrsr $)$ over the graph of acquired data to find $\mathrm{x}(0), \mathrm{y}(0), \mathrm{x}(\mathrm{t}), \mathrm{y}(\mathrm{t}), \mathrm{x}(\infty), \mathrm{y}(\infty)$ and time $(\mathrm{t})$ values and calculated changes in those coordinate values. The symbol $\infty$ is intended to represent some time $t$ at steady-state.

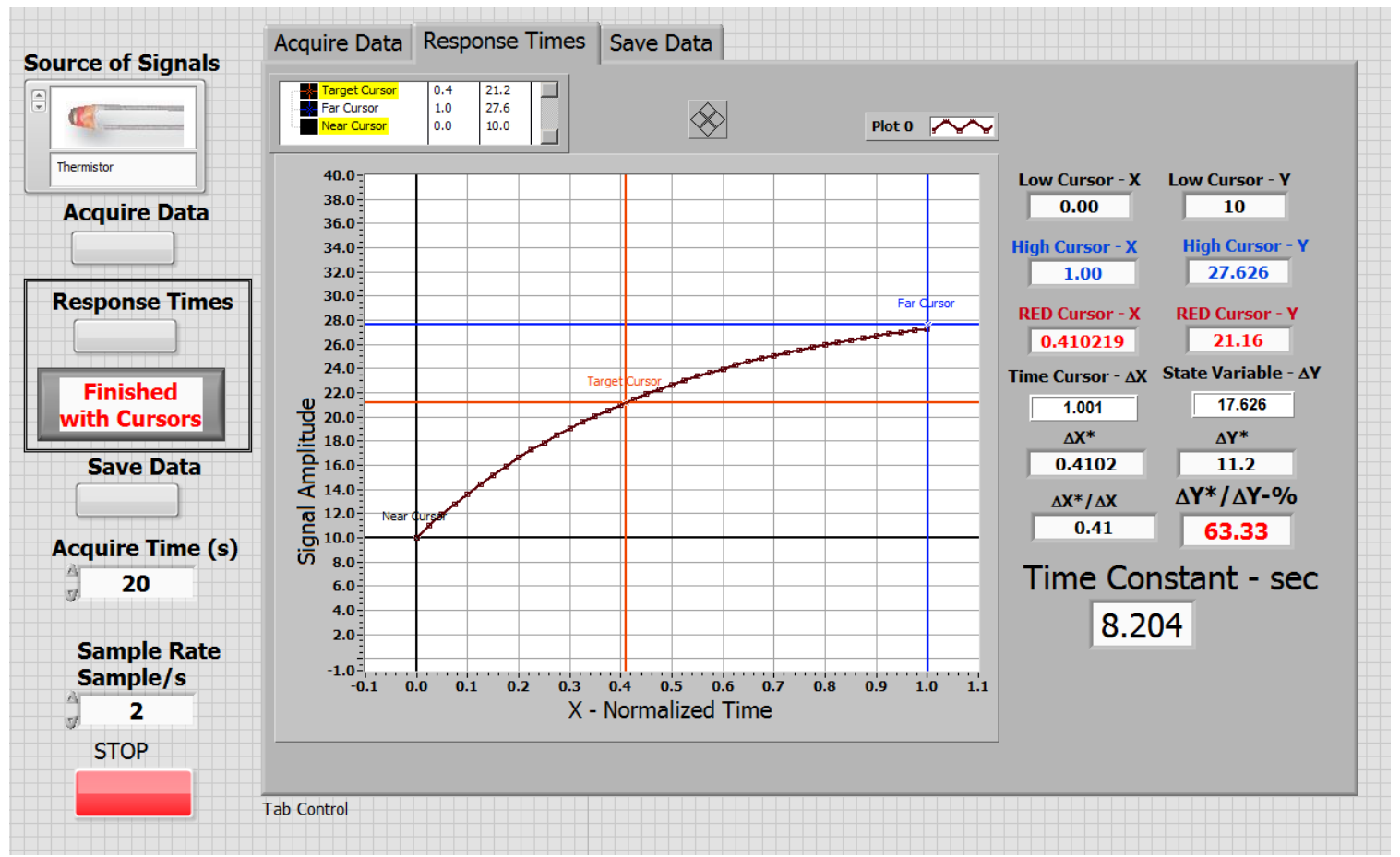

Figure 5. LabVIEW Front Panel for 63\% Temperature Rise Example. 


\section{Large Water Flow Measurements Laboratory}

Another signature exercise is the large water activity in a unique facility at this instructional location. Large scale water flow measurements need to be as convenient as possible for irrigation, domestic water supply, and ecological water supplies, but also accurate and reliable. For small flow rates such as domestic water systems, a weighing tank may be sufficient as a calibration device. However, with large-scale water flow rates in hundreds of cubic meters per minute, a weighing tank becomes impractical. Certified pipeline flow meters, such as a commercial venturi system have a fundamental theoretical basis using fluid mechanics, and are therefore important devices for cross-checking, standardizing, or validating other commercial impeller-type transducers and flow meters. The venturi meter has a lower head loss factor than the orifice plate, although orifice plates are usually cheaper to make. Impeller-type meters are convenient, but as mechanical devices are subject to wear and tear. Mechanical flow meters do easily decalibrate and must be checked occasionally. When measuring water flow rates in an open channel, weir or flume meters are usually the measurement devices of choice, but also require calibration.
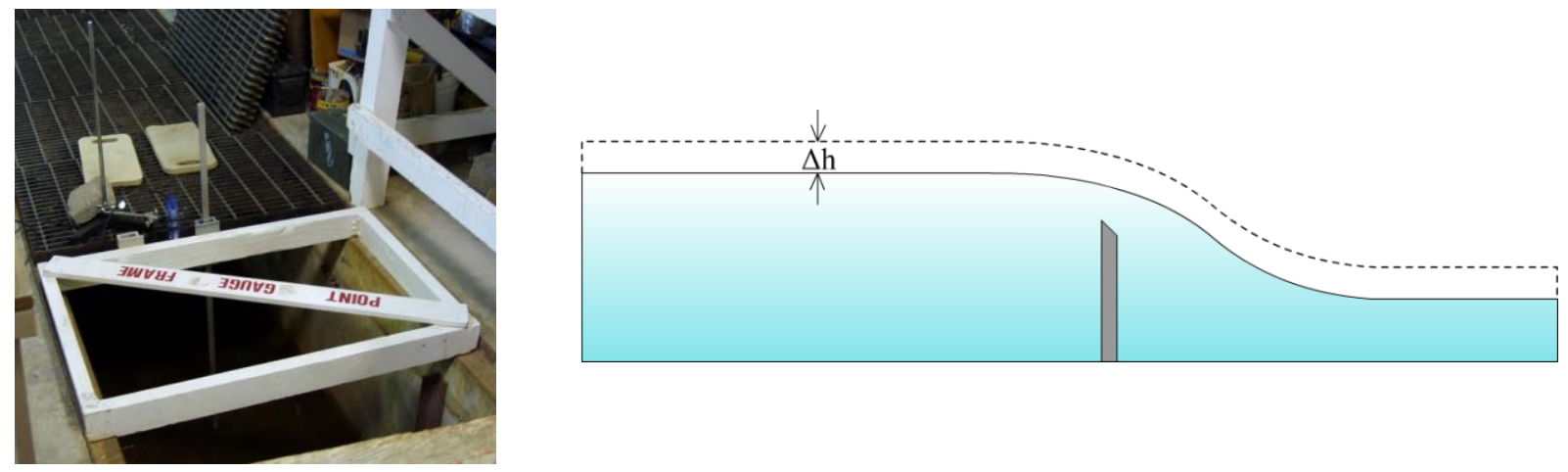

Figure 6. V-notch weir, point gage, and ultrasonic proximity sensor to measure the change in flow height, which can be converted to a flow quantity rate.

A manual sighting point gage and a Senix ultrasonic proximity sensor (Senix Corp., Bristol, VT) were used to determine the hydraulic height over an open channel v-notch weir (Figure 6). A LabVIEW Modbus Senix DAQ program was used with a Senix Ultrasound proximity sensor to measure open channel flow. A NI multifunction module was used to count pulses for a pipe flow sensor.

\section{Gasoline Engine Performance Testing}

To revisit principles of thermodynamics previously taken as a fundamentals course as sophomores and as a practical exercise, a power laboratory is introduced. Dynamometers are commonly used for measuring engine performance, as shown in Figure 7. They effectively act as a brake on an engine, applying a load and causing the engine to "lug." This allows for simulation of real-life load applications, and to check whether the engine will perform to its specifications. The actual performance of the engine is then measured through a set of desired quantities, which include engine torque, speed, and fuel efficiency. In addition, the fuel flow to the engine must also be measured. This allows for a full overview of how the engine should behave when used in an applied application, and potentially highlights problems that can be corrected before the engine is 
placed in a consumer's hands.

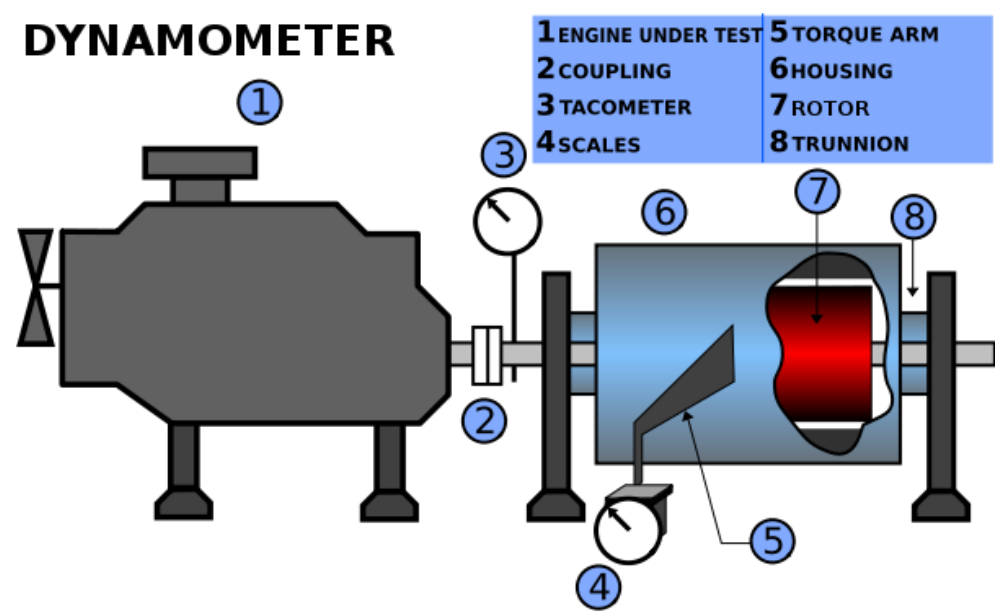

Figure 7. The crank shaft of a test engine attached to a dynamometer (courtesy: https://en.wikipedia.org/wiki/Dynamometer).

An instrumentation system with LabVIEW® operating software was provided and is designed to measure several performance parameters of a test engine. The actual tests were operated by a technician. However, students took places in the provided chairs while the results were being presented by the test computer on a nearby projection screen. Data included: output torque and engine speed, various temperatures of engine fluids, fuel flow rate and oil and turbo boost pressures. To measure these physical phenomena, the following sensors shown in Table 3 were used.

Table 3. Electronic sensors used and data generated.

\begin{tabular}{|c|c|c|c|}
\hline Sensor & Sensor Type & Parameter & $\begin{array}{l}\text { National Instruments } \\
\text { DAQ Linkages }\end{array}$ \\
\hline Speed Sensor & Hall Effect & Engine Rotational Speed, $\dot{\mathrm{n}}$ & $\begin{array}{l}\text { NI cDAQ-9184 - 32-bit } \\
\text { voltage inputs, 32-bit counter }\end{array}$ \\
\hline $\begin{array}{c}\text { Torque Load } \\
\text { Cell } \\
\end{array}$ & Strain Gage & Torque Applied, $T$ & \multirow{2}{*}{$\begin{array}{l}\text { NI 9219 - } 4 \text { channel } \\
\text { universal analog input with } \\
\text { support for thermocouples, } \\
\text { RTD, } \\
\text { resistance, thermistors, } \\
\text { bridge, voltage, and current } \\
\text { measurements }\end{array}$} \\
\hline $\begin{array}{l}\text { IRt/c Infrared } \\
\text { Thermocouple }\end{array}$ & Type K & Transmission Temperature & \\
\hline Postal Scale & Fuel Mass & Fuel Remaining, $\mathrm{m}_{\mathrm{f}}$ & NI VISA USB \\
\hline Speed Sensor & Hall Effect & $\begin{array}{c}\text { Dynamometer Rotational } \\
\text { Speed }\end{array}$ & $\begin{array}{l}\text { NI cDAQ-9184 - 32-bit } \\
\text { voltage inputs, 32-bit counter }\end{array}$ \\
\hline
\end{tabular}


The LabVIEW program was used to observe real-time values and settings imposed for the dynamometer and engine. Those results were projected onto large screen for the students in the Splinter Power Laboratory (East Campus). The data points were collected and plotted on the screen in real time as sampled means and standard deviations using a designated collection time of one minute for each set of test conditions imposed. The individual tests and sample data were also recorded by the students and their report was to complete the final performance calculations.

Table 4. Formulas for Power laboratory (SI units).
a. $\quad$ Power,
$\dot{\mathrm{W}}_{\mathrm{bp}}=\frac{2 \cdot \pi \cdot \dot{\mathrm{n}} \cdot T}{60}$
$[\mathrm{kW}]$

Where: $\dot{n}$ is the dynamometer rotational speed, RPM.

$T$ is the applied torque, $\mathrm{kN}-\mathrm{m}$.

b. Rate of mass Fuel usage, $\quad \dot{\mathrm{m}}_{\mathrm{f}}=\frac{\Delta \mathrm{m}_{\mathrm{f}}}{\Delta \mathrm{t}} \quad[\mathrm{kg} / \mathrm{s}]$

Where: $\Delta \mathrm{m}_{\mathrm{f}}=\mathrm{m}_{\mathrm{f}, \mathrm{i}}-\mathrm{m}_{\mathrm{f}, \mathrm{i}-1}, \mathrm{~kg}$.

And $\Delta t$ is the time between fuel mass readings $t_{i}-t_{i-1}, s$.
c. Specific Fuel Consumption,

$$
\mathrm{SFC}=\frac{\dot{\mathrm{m}}_{\mathrm{f}}}{\dot{\mathrm{W}}_{\mathrm{bp}}}
$$
$[\mathrm{kg} / \mathrm{s} / \mathrm{kW}]$
d. Fuel Efficiency,
$\eta_{\mathrm{BT}}=\frac{\dot{\mathrm{W}}_{\mathrm{bp}} \cdot 100}{\dot{\mathrm{m}}_{\mathrm{f}} \cdot \mathrm{q}_{\mathrm{f}}}$
[percent]

\section{Speed Regulation of a DC motor with Pulse Width Modulation}

During this signature lab, students used a method called "Pulse Width Modulation (PWM)" to regulate the speed of a DC motor. The DC motor is probably the most important type of actuators used for instrumentation and control. It is widely used in agricultural machinery, medical robots, home appliances, etc. Numerically controlled lathes (mills) and 3D printing are two modern technologies enabled by the precision control of the speed and position of motors (DC motor and stepper motor).

The NI MyDAQ AO (analog output) line was used to produce PWM signals. The NI ELVISmx Function Generator program was used (Figure 8). The signals generated were square waves from 0 to $5 \mathrm{~V}$. Zero voltage was used to turn off a power transistor (thus cut off the current flow through the DC motor) and five volts was used to turn it on. 


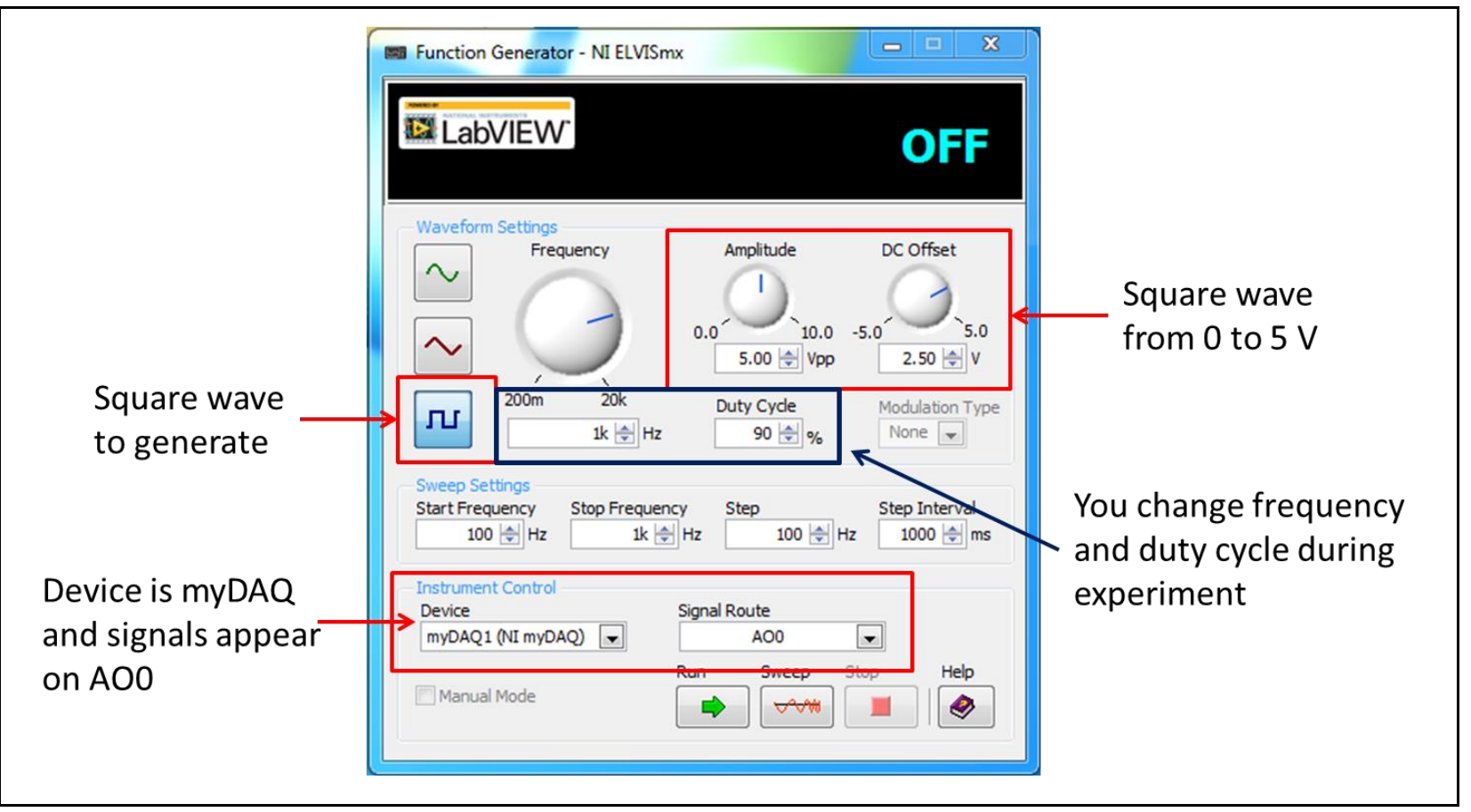

Figure 8. The setting of the NI ELVISmx Function Generator program to generate PWM signals for the motor drive (Courtesy:NI.com).

\section{$\underline{\text { Student Team Projects }}$}

The final six weeks of the class were devoted concurrently to student team projects. Team student instrumentation and controls projects are selected from a prescribed list provided by the instructor. The students developed the projects as a group and presented them as posters at an annual Department open house. The open house includes invited other students, alumni, faculty, administrators and potential employers. Team sizes are either three or four members. The final written term paper was graded according to the instrument shown in Appendix B. A brief summary description of selected projects for the year 2015 is given in Table 5.

Table 5. 2015 Student Team Projects

\begin{tabular}{|l|c|l|l|}
\hline Team & Team size & \multicolumn{1}{|c|}{ Topic } & Theme \\
\hline Group 1 & 4 & Infant Incubator sensing and control & Biomedical \\
\hline & & & \\
\hline Group 2 & 4 & Light-intensity stabilizing system & General \\
\hline & & & Biomedical \\
\hline Group 3 & 4 & Physiological Response to Tobacco Intake & \\
\hline & & & General \\
\hline Group 4 & 3 & Object color shape detection on conveyor belt & \\
\hline & & & Biomedical \\
\hline Group 5 & 3 & Measurement of Valgus Collapse & \\
\hline
\end{tabular}




\begin{tabular}{|c|c|c|c|}
\hline Group 6 & 4 & Monitor and test fertigation in greenhouse & Agricultural \\
\hline Group 7 & 3 & $\begin{array}{l}\text { Fruit identification with color detection and } \\
\text { machine vision }\end{array}$ & Agricultural \\
\hline Group 8 & 4 & Human body intoxication sensing & Biomedical \\
\hline Group 9 & 3 & Effect of sugar on EKG and LabVIEW analysis & Biomedical \\
\hline Group 10 & 3 & Data acquisition for a DANFOSS tractor controller & Agricultural \\
\hline Group 11 & 4 & Muscle tightness of the body & Biomedical \\
\hline Group 12 & 3 & UAV for crop monitoring & $\begin{array}{l}\text { Agricultural / } \\
\text { Environmental }\end{array}$ \\
\hline Group 13 & 3 & $\begin{array}{l}\text { 3D heat and water flow through soil - sensing and } \\
\text { visualization }\end{array}$ & $\begin{array}{l}\text { Agricultural / } \\
\text { Environmental }\end{array}$ \\
\hline Group 14 & 4 & Force measurement for Chase Hall doors & $\begin{array}{l}\text { Mechanical / } \\
\text { Agricultural }\end{array}$ \\
\hline Group 15 & 4 & Water quality measurement & Environmental \\
\hline Group 16 & 4 & EEG measurement & Biomedical \\
\hline Group 17 & 4 & Human body stress level detection & biomedical \\
\hline
\end{tabular}

\section{Student Acceptance}

Class size has ranged from 8 to 70 students since its inception in 1987. The focus is primarily the application of electronics and electrical principles. However, each emphasis area can explore relevant applications. Student overall reaction to this class has always been very good. Biological systems engineers receive a once in a life-time opportunity to participate in two predominantly agricultural activities: (namely water flow for irrigation, supply, and drainage and a power lab with an internal combustion engine. The overall class score was (near 3 on a 4 point scale). The overall instructor score was (above 3 on a 4 point scale). Students were quite complimentary about the course and that the instructor(s) did a good job. The material was considered very relevant. Examinations primarily weekly quizzes were considered fair. Posters on team projects were well-done at the open house. Final project reports were well-written. 


\section{Conclusions}

"Instrumentation and Controls" has been a core class for both agricultural and biological systems engineering students at the University of Nebraska for many years. Class size has ranged from 10 students in 1987 to 60 students (more recently in 2015). Three laboratory sections were held during the fall of 2015 (an average of 26 students per section). With two participating instructors and student team work, the class size of this hands-on course has not been an issue. Improvements and updates are made annually to the textbook. The paradigm of continuous improvement for ABET can be achieved based on student performance, feedback, and possible new instrumentation innovations in the discipline. The chapters of our textbook and supplemental notes and laboratory handouts provides an flexible arsenal of instructional material, problems to be solved, and an archive to select from each semester. This course has had a major impact on sustained ABET accreditations for the two engineering degree programs in this department. Using the electronic grading for homework and examinations allows archiving of all student materials as evidence for the course.

\section{Bibliography}

1. Johnson, C.D., 2006. Process Control Instrumentation Technology $\left(8^{\text {th }}\right.$ Edition). Pearson, Prentice Hall. Columbus, $\mathrm{OH}$.

2. Northrop, R.B., 1997. Introduction to Instrumentation and Measurements. CRC Press, NY.

3. Webster, J.G., 1999. The Measurement, Instrumentation, and Sensors Handbook. CRC and IEEE Press., Baca Raton, FL.

4. Nachtigal, C.W., 1990. Instrumentation and Controls, Fundamentals and Applications. John Wiley and sons, NY.

5. Mitchell, B.W., 1983. Instrumentation and Measurement for Environmental Sciences. American Society of Agricultural Engineers, St. Joseph, MI.

6. Dally, J.W., W.F. Riley, and K.G. McConnell, 1993. Instrumentation for Engineering Measurements, Second Edition. John Wiley and sons, Inc., New York.

7. Carr, J.J., 1996. Elements of Electronic Instrumentation and Measurement, Prentice Hall, Englewood Cliffs, NJ.

8. Turner, J. and M. Hill, 1999. Instrumentation for Engineers and Scientists. Oxford Science Press, NY.

9. Ramsay, D.C., 1996. Principles of Engineering Instrumentation, John Wiley and sons, NY.

10. Khalid, S.F., 2000. LabWindows/CVI Programming for Beginners. Prentice Hall, Upper Saddle River, NJ.

11. Olansen, J.B. and E. Rosow, 2002. Virtual Bio-Instrumentation. Biomedical, Clinical, and Healthcare Applications in LabVIEW. Prentice Hall, NY.

12. Travis, J. and J. Kring, 2006. LabVIEW for Everyone. Prentice Hall, NY.

13. Khoo, M.C.K., 1999. Physiological Control Systems. IEEE Press, NY.

14. Meyer, G.E. and Yufeng Ge, 2015. Instrumentation and Controls for Agricultural and Biological Engineering Applications, using LabVIEW ${ }^{\circledR}$ and other Modern tools as Support Systems. Unpublished set of notes. University of Nebraska.

15. Meyer G.E., J. Subbiah, and K. Cluff, 2012. Electronic Student Homework Management Systems for Continuous Improvement and Program Assessment. Paper 4811. ASEE Annual Conference Proceedings, San Antonio, Texas (on CD). 


\section{Appendix A.}

Catalog AGEN/BSEN 460/860. Instrumentation and Controls (3 cr) Lec 2. Lab 2. Prereq:

Description: Analysis and design of instrumentation and controls for agricultural and biological production, management, and processing. Theory of sensors and transducers, analog and digital electrical control circuits, and the interfacing of computers with instruments and controls. Emphasis on signal analysis and interpretation for improving system performance.

Text Books:

Instrumentation and Controls for Agricultural and Biological Engineering Applications, using LabVIEW® and other Modern tools as Support Systems by G.E. Meyer and Yufeng Ge, University of Nebraska (Unpublished Textbook).

Format: This course is 3 credits ( 2 weekly lectures and a two-hour laboratory). 
Appendix B. FINAL REPORT - SCORE SHEET - 125 Points

\begin{tabular}{|c|c|c|c|}
\hline CATEGORIES & $\begin{array}{l}\text { POSSIBLE } \\
\text { POINTS }\end{array}$ & $\begin{array}{l}\text { POINTS } \\
\text { GIVEN }\end{array}$ & COMMENTS \\
\hline SIGNED LETTER OF TRANSMITTAL & \multicolumn{3}{|c|}{$\begin{array}{l}\text { Report must be signed by all team members, } \\
\text { signifying all have contributed! }\end{array}$} \\
\hline REPORT CONTENT AND FORMAT & & & \\
\hline Summary - Single descriptive paragraph or abstract. & 5 & & \\
\hline $\begin{array}{l}\text { Background and Literature Review - Cites useful } \\
\text { literature, previous instrumentation approaches, and } \\
\text { describes purpose and impact of the project. }\end{array}$ & 15 & & \\
\hline $\begin{array}{l}\text { Objectives - Overall objective and 1-2 sub } \\
\text { objectives. }\end{array}$ & 5 & & \\
\hline $\begin{array}{l}\text { Procedure/ Methods - Sensors used. Data } \\
\text { acquisition method. Appropriate equations, units, } \\
\text { numbered, and cited. Refers to sample calculations } \\
\text { or results in appendix. Support with pictures, figures } \\
\text { and/or tables, as appropriate. }\end{array}$ & 20 & & \\
\hline $\begin{array}{l}\text { Results and Discussion - Reports details and results } \\
\text { of development efforts, methods, testing, with table } \\
\text { and figure support. }\end{array}$ & 20 & & \\
\hline $\begin{array}{l}\text { Conclusions - Appropriate conclusions that match } \\
\text { objectives. Suggestions for future work. }\end{array}$ & 10 & & \\
\hline References (Complete citations - ASAE method). & 5 & & \\
\hline $\begin{array}{l}\text { Figures and Tables - Appropriate amount of } \\
\text { significant digits, information displayed, correctly } \\
\text { justified, labeled, footnotes, and captions in the } \\
\text { correct position. Landscapes attached correctly to } \\
\text { the report. Stands by themselves. }\end{array}$ & 10 & & \\
\hline $\begin{array}{l}\text { Appendices - Appropriate supporting material. } \\
\text { Examples: computer code used, manufacturer's } \\
\text { specific sheets, sample calculations, samples of raw } \\
\text { data, and cost data (not required, unless requested). }\end{array}$ & 10 & & \\
\hline OVERALL REPORT APPEARANCE & $\mathbf{0}$ & & \\
\hline $\begin{array}{l}\text { Neatness and Writing Quality - Proper spacing, } \\
\text { justification, proper grammar, correct spelling, and } \\
\text { page numbers. Drawings and sketches are neat and } \\
\text { properly labeled. }\end{array}$ & 15 & & \\
\hline $\begin{array}{l}\text { Overall Creativity - Shows interest and enthusiasm } \\
\text { in project. }\end{array}$ & 10 & & \\
\hline FINAL TOTAL SCORE & 125 & & \\
\hline
\end{tabular}

